\title{
ПРЕДВИДЕНИЕ - ПАНАЦЕЯ ИЛИ МИФ В УПРАВЛЕНИИ ХОЗЯЙСТВЕННЫМИ СИСТЕМАМИ
}

\author{
(c) 2020 Забелин Борис Федорович \\ кандидат экономических наук \\ Институт промышленного менеджмента, экономики и торговли \\ Санкт-Петербургский политехнический университет Петра Великого (СПбПУ), \\ Россия, Санкт-Петербург \\ E-mail: zabelinbf@mail.ru \\ (c) 2020 Наумова Ольга Николаевна \\ кандидат экономических наук, доцент \\ Институт промышленного менеджмента, экономики и торговли \\ Санкт-Петербургский политехнический университет Петра Великого (СПбПУ), \\ Россия, Санкт-Петербург \\ E-mail: oseeleva@mail.ru

\section{(c) 2020 Никишин Вадим Михайлович} \\ кандидат экономических наук, доцент \\ Санкт-Петербургский государственный электротехнический университет «ЛЭТИ» \\ им. В. И. Ульянова (Ленина), Россия, Санкт-Петербург

\section{(c) 2020 Хатанзейский Константин Кимович} \\ кандидат философских наук, кафедра «Реклама и связи с общественностью» \\ Санкт-Петербургский политехнический университет Петра Великого (СПбПУ), \\ Россия, Санкт-Петербург \\ E-mail: hatanzkk@mail.ru

\section{(c) 2020 Финько Алла Васильевна} \\ кандидат экономических наук, доцент \\ Институт промышленного менеджмента, экономики и торговли \\ Санкт-Петербургский политехнический университет Петра Великого (СПбПУ), \\ Россия, Санкт-Петербург \\ E-mail: kalipsoalla@mail.ru
}

Задача науки относительно предвидения: создать критерии отличий научного предвидения от мистических прозрений. Сила предвидения как движения в том, что это стимул к реализации лучшего по сравнению с настоящей реальностью. Приведенные аспекты методологической оценки предвидения не имеют прецедентов воплощения в содержании методического обеспечения практики реализации опережающей, применительно к управлению хозяйственными системами, деятельности. В настоящий момент актуализируется потребность в разработке новой методологии назначения этого важного для повышения эффективности управления хозяйственными системами явления.

Ключевые слова: научное предвидение, прогнозирование, познавательная стратегия, классификация, прогностическое отражение, опережающая деятельность, методология назначения.

Современное состояние исследования предвидения в управлении хозяйственными системами характеризуется наличием методологических и содержательных противоречий. В научной литературе приводятся определение термина «предвидение», отражающие, преи- мущественно профессиональную принадлежность авторов (философ, психолог, экономист и др.), рассматриваются различные его аспекты в теории и практике профессиональной деятельности. Однако представляется это в описательной форме, в интерпретации предвидения как 
подсознательного феномена на основе сложившихся в литературе суждений. При этом термин «проблема» упоминается достаточно часто, но не редко при полном игнорировании принципов формирования проблемной ситуации, включающих:

- постановку проблемного вопроса, интерпретацию содержания условий проблемы как системы предметных отношений;

- направления и этапы решения;

- детерминанты выбора операционных структур формирования образа объекта предвидения.

Феномен предвидения с точки зрения здравого смысла сомнителен, так как легко спутать научное предвидение и провидения ясновидцев. В мире науки, если речь идет о будущем возникает требование закономерности в той форме, когда требуется логика, применение теории познания, размышления, основанные на рациональности.

Исторической основой предвидения как научной категории являются понятия «утопия» и «эсхатология», связанные, прежде всего, с мистической интуицией, и если рассматривать предвидение с позиций науки, то, прежде всего, придется расстаться с мистикой. Задача науки относительно предвидения: создать критерии отличий научного предвидения от мистических прозрений. В этом плане философ и социолог К.Поппер предложил два уровня анализа: логику и психологию познания, предвидение, по мнению философа, начинается с «горизонта ожиданий», совокупности ожиданий как бессознательных, так и сознательных, «...горизонт ожиданий это поле действия, система координат, в рамках которых реализуется опыт человека находящегося в поисках смысла» [1].

Сила предвидения как движения в том, что это стимул к реализации лучшего по сравнению с настоящей реальностью. Предвидение надо воспринимать как форму саморефлексии и предостережения, мыслить через границы возможного, искать новое, осуществляя постепенное творческое пересоздание жизни.

С другой стороны отсутствие четко поставленных проблем в сфере исследования явлений предвидения обуславливает их определения методологически недействительными для развития теории и практики опережающего управления хозяйственными системами. Содержащиеся в литературе определения чрезвычайно однообразны и основываются на феноменализации отдельного компонента познавательной деятельности при подведении их к сущности основных критериев реального бытия данного явления. Для одних авторов - это не наблюдаемость объекта предвидения; для других - функция идеального воспроизведения будущего; для третьих - общенаучные и частнонаучные принципы оценки предметов, явлений, фактов и существующих между ними отношений (принципы повторяемости, развития, детерминизма, случайности и др.). Идет диалог между реалистами и теми, кто видит будущее в ином ключе, в ином ракурсе, они предлагают нечто идеальное, далекое от реальности, это люди, имеющие творческий потенциал, они умеют творчески осмыслить окружающий мир и предложить новое, то, что иногда противоречит научной теории. Идея научного определения «предвидения» тесно связана с идеей этико-морального развития общества, проблемой смысла жизни, смерти как конечного аспекта бытия. Например, критический анализ концепции социальноисторической эволюции, попытка культурологов преодолеть линейную схему развития истории, привела к появлению цивилизационного подхода, концепция появилась на основе осмысления деградации локальных культур. Научное предвидение делает попытки вариативного решения глобальных проблем, минимизации негативных последствий научно-технического прогресса и катастрофического загрязнения окружающей среды.

Определение предвидения окажется полноценным, методологически действенным, если в нем будут отражены разнопредметные разнофункциональные проявления. Отсюда закономерна и критика соответствующих определений предвидения, вполне обосновано обобщённая в работах философа А.Г.Никитиной [2]. Она особо обращает внимание на то, что под предвидением понимается некоторый результат, уже полученное знание. Иначе говоря, предвидение представляется лишь некоторым утверждением (из группы возможных утверждений).

В таких случаях учитывается лишь один фрагмент структуры реального предвидения, а не единство многообразных характеристик объекта. В результате то, что называется предвидением, является лишь результатом процесса предвидения, его конечным итогом.

Данное обобщение А.Г.Никитина сопро- 
вождает уже сложившимся в науке мнением о том, что вернее было бы понимать предвидение как процесс исследования, как некоторую целостную операцию, процедуру познания возможных состояний систем, явлений в будущем. Философия так устроена, что она критикует современную ей культуру, в силу свойственной ей процессуальности она пытается заглянуть в будущее, чтобы определить изменения в структуре культуры будущего. Окружающий мир наполнен противоречиями и целью философии как научного мировоззрения, является оценка всей системы цивилизационного развития и обоснование вариантов позитивной эволюции.

Научное знание в своем развитии опирается, прежде всего, на достоверные, проверенные факты, формирующие предпосылки предвидения. До того момента когда ученые создадут теоретическую систему, знание развивается гипотетически, идет процесс «нащупывания» нового знания о мире. К.Поппер обозначил этот процесс «познавательной стратегией», где даже ложность предположения является плюсом в познании истины [3].

Другим недостатком определений выступает тот факт, что в таких определениях объектом предвидения считается лишь будущая действительность, т.е. такие явления, процессы, которые не существуют в момент предвидеологического исследования, но, возможно, появятся в будущем.

При рассмотрении соотношения понятий «предвидения» и «прогнозирования», в литературе очевидна понятийно-терминологическая неразбериха: для одних авторов прогнозирование более широкое понятие, для других - более узкое - оно лишь компонент предвидения, его конкретно-логическое выражение. Во избежание терминологических повторов авторы многих публикаций предвидение называют прогнозированием, а прогнозирование - предвидением в зависимости от контекста. Философия как инструмент научного прогнозирования анализирует действительность, выявляет потенциальные возможности и строит предположения относительно ее возможного развития.

В своем понимании предвидения и прогнозирования мы придерживаемся точки зрения тех авторов, которые не считают их синонимами и рассматривают предвидение как более общее понятие по отношению к прогнозированию, придавая последнему роль одного из видов кон- кретизации научного предвидения (Г.Е.Глезерман, А.Г.Никитина, В.Н.Ярская, Б.А.Яхонтов и др.).

В.Н.Ярская сформулировала обобщающее определение понятию предвидение: «Предвидение обозначает весь комплекс прогностического отражения на уровне человека, от прогностической функции эмоций до теоретического предсказания в науке» [4]. Тем не менее в сфере научного предвидения до того пока гипотеза не пройдет через «минное поле» научной критики она имеет статус предположительного знания. «Критическое мышление в противовес догматическому имеет не подтверждения, а опровержения, гипотезы, возникающие в рамках такого мышления, формулируются с прицелом на критическое обсуждение и строгие проверки, следовательно, критичность обуславливает фальсифицируемость, эмпиричность и научность знания» [5].

Для реализации предвидения в качестве средства, опережающего управления хозяйственными системами, необходима классификация его видов.

Такая классификация может осуществляться по следующим направлениям:

1. В соответствии с ролью субъекта в опережающих управленческих действиях предвидение разделяется на два вида:

- пассивное предвидение, когда будущему наступлению события не сопутствует вмешательство субъекта управления, либо в этом у него нет практической необходимости;

- практическое предвидение, включающееся непосредственно в управленческую деятельность специалиста.

2. По срокам достижения (наблюдения) предвидимого объекта предвидения разделяются на оперативные (текущие), краткосрочные, среднесрочные и долгосрочные. Определяющие эти сроки критерии зависят от предметновременных параметров управленческой деятельности, в структуре которой осуществляется предвидение.

3. По специфике процесса познания, обуславливающего формирование предвидимого объекта. При этом предвидение реализуется:

- как эмпирическое, основанное на повседневном опыте управленца и осуществляющееся в сфере реального развития процессов, явлений и существующих между ними отношений. Эмпирическое предвидение всегда осуществляется 
в виде интуитивного действия и движения мысли к объекту предвидения;

- научное предвидение, осуществляемое как видение будущего на основе использования законов, теорий, методов теории познания и действенных методик. Результатом научного предвидения выступает система выводов по будущему управлению развитием хозяйственных систем.

Проблемная ситуация возникает в результате противоречия фактов и законов, появляются гипотезы и предположения, предвидение-это попытка привести все к логике и объяснить как бы необычно это не казалось. В сфере научного предвидения или «предвосхищения» объективность достигается через критические установки, а уже затем через логику. Научное предсказание касается, прежде всего, «неорганического тела цивилизации» (термин применил Степин В.С. [6]) имеется в виду эволюция науки, создание технических устройств, которые выступают продолжением человеческого тела. Сложность анализа феномена причинности, в поисках основы предвидения, заключается в выявлении смысла и связи явлений, закономерностей, в привычке человека логически анализировать ассоциацию событий. Причинность, как начало предвидения, является «регулятивным принципом познания», «...в своих конкретных формулировках причинность никогда не реализовывалась как действительно всеобщая связь, обнаруживая свою ограниченность всякий раз при очередном переходе к исследованию новых уровней строения и организации окружающего мира» [7].

Можно разделить предвидение на два типа: пророческое и технологическое. Первое определяет событие, которое мы не можем предотвратить, например, взрыв вулкана, второе образует основу для технологических предсказаний, например, саморазвивающиеся компьютеры. Человек может повысить вероятность «...сохранить баланс между пророческими и технологическими, между прогнозированием и планированием, между предвидением и действием» [8].

4. По операциональной структуре предвидение разделяется на следующие виды:

- предвидения-аналогии (основанные на использовании классического механизма вывода по аналогии) - средство получения наиболее вероятностного, но наиболее оригинального будущего. «Творчество нового, в том числе и творчество самого человека, постоянно изменя- ет ситуацию, ограничивает наши возможности предвидения будущего, но в то же время делает свободу воли реальным фактором в формировании будущего» [9].

- предвидения-модели. Моделирование в процессе предвидения исключительно удобно в том плане, что создаваемые познавательные модели чаще всего трансформируются непосредственно в операционные структуры, включающие в себя предвидение деятельности определенного содержания. В таких случаях модель представляет содержание и поэтапность действий, позволяют определить ранее неиспользовавшиеся средства деятельности, способные обеспечить ее достоверность, особенно при неопределенности и риске.

- предвидение на основе собственного закона, когда будущее формируется в анализе основного закона функционального бытия исследуемого объекта и связанных с ним законов той сферы деятельности, к которой этот объект принадлежит. Результат предвидения в данном случае определяется специфическими проявлениями закона, главным из которых является степень его общности: чем выше степень общности используемого в основании предвидения закона, тем более конкретным в своем бытии и своих функциональных характеристиках оказывается объект.

- научное предвидение;

- гипотетическое предвидение в виде классического механизма формирования гипотезы или использования гипотетических фактов качестве предвосхищающего объект предвидения материала;

- предвидение-экстраполяция на временной период;

- восстановительное предвидение, механизм которого представляет собой воссоздание событий, явлений, фактов прошлого по их сохранившимся фрагментам - предметам, содержанию официальных документов и художественных текстов;

- реверсивное предвидение явлений, тенденций от настоящего к прошлому;

- фантастическое предвидение.

5. По виду предметности результата предвидения разделяются:

- на законы, закономерности, тенденции во взаимодействии практических, художественных и теоретических объектов окружающего нас природного и общественного мира; 
- на объекты, модели нового технического объекта или способа поведения управляемой системы при внесении в нее «возмущающих» факторов и т.д.

6. По особенностям процессуальной функции предвидение представляется в трех видах:

- побудительное предвидение;

- ориентирующее предвидение;

- гносеологическое предвидение.

Предсказание можно определить как развитие познавательной стратегии, когда мы ищем способы подтверждения прогрессивности, теории которой придерживаемся в научном исследовании. В значительной степени предвидение это ожидание, как работа интуиции, на следующем этапе в виде наблюдения и анализа, предвидение становится гипотезой. Участие логики и воображения в анализе проблемной ситуации приводит к созданию предположения.
Приведенные аспекты методологической оценки предвидения не имеют прецедентов воплощения в содержании методического обеспечения практики реализации опережающей, применительно к управлению хозяйственными системами, деятельности. В настоящий момент актуализируется потребность в разработке новой методологии назначения этого важного для повышения эффективности управления хозяйственными системами явления. Формирование методологии, способной объяснять и направлять практические процессы всех классификационных видов предвидения, возможно на основе аналогии, увязывающей в своем механизме данное явление с процессами управления хозяйственными системами, близкими ему операционально, результативно, функционально и целеобусловлено.

\section{Библиографический список.}

1. Поппер К. Р. Объективное знание. Эволюционный подход. М., 2002.

2. Никитина А.Г. Философия и методология науки. Аспект Пресс. М.,1996.

3. Поппер К. Р. Логика и рост научного знания. М.,1983.

4. Ярская В.Н. Научное предвидение. Вопросы методологии.-Саратов, 1980.- С. 20.

5. Пирожкова С. В. Проблема предсказаний в социальной философии К. Поппера// Философские исследования. 2007. № 3-4.

6. Степин В. С. Теоретическое знание. М., 2003.

7. Мамчур Е. А. Причинность как идеал научного познания. //Философия, наука, цивилизация. М.,1999.

8. Пирожкова С.В.Эволюция форм научного предвидения: смен типов научной рациональности и концепция технонауки // Первые Степинские чтения. Современный этап развития науки и кризис техногенной цивилизации: материалы конференции с международным участием (Москва, 5-6 ноября 2019 г.) / Отв. ред. В. Г. Буданов, В.А, Лекторский. Курск: Университетская книга, 2019. С. 51-55.

9. Юлина Н.С. Философия К. Поппера: мир предрасположенностей и активность самости// Вопросы философии. 1995. № 10 . 